\title{
Adult Neurogenesis and Glial Oncogenesis: When the Process Fails
}

\author{
Chary Marquez Batista, ${ }^{1,2}$ Eric Domingos Mariano, ${ }^{1,2}$ \\ Breno José Alencar Pires Barbosa, ${ }^{1}$ Matthias Morgalla, ${ }^{3}$ Suely Kazue Nagahashi Marie, ${ }^{1,2}$ \\ Manoel Jacobsen Teixeira, ${ }^{1}$ and Guilherme Lepski ${ }^{1,2,3}$ \\ ${ }^{1}$ Department of Neurology, School of Medicine, University of São Paulo, Avenida Dr. Arnaldo 455, LIM 15, 4th Floor, \\ 01246-903 Cerqueira Cesar, SP, Brazil \\ ${ }^{2}$ Center for Cellular and Molecular Studies and Therapy-NAP-NETCEM, University of São Paulo, Brazil \\ ${ }^{3}$ Department of Neurosurgery, Eberhard Karls University, Tuebingen, Germany
}

Correspondence should be addressed to Guilherme Lepski; lepski@usp.br

Received 16 November 2013; Accepted 29 January 2014; Published 11 March 2014

Academic Editor: Almudena Fuster-Matanzo

Copyright (c) 2014 Chary Marquez Batista et al. This is an open access article distributed under the Creative Commons Attribution License, which permits unrestricted use, distribution, and reproduction in any medium, provided the original work is properly cited.

\begin{abstract}
Malignant brain tumors, including glioblastoma multiforme (GBM), are known for their high degree of invasiveness, aggressiveness, and lethality. These tumors are made up of heterogeneous cell populations and only a small part of these cells (known as cancer stem cells) is responsible for the initiation and recurrence of the tumor. The biology of cancer stem cells and their role in brain tumor growth and therapeutic resistance has been extensively investigated. Recent work suggests that glial tumors arise from neural stem cells that undergo a defective process of differentiation. The understanding of this process might permit the development of novel treatment strategies targeting cancer stem cells. In the present review, we address the mechanisms underlying glial tumor formation, paying special attention to cancer stem cells and the role of the microenvironment in preserving them and promoting tumor growth. Recent advancements in cancer stem cell biology, especially regarding tumor initiation and resistance to chemo- or radiotherapy, have led to the development of novel treatment strategies that focus on the niche of the stem cells that make up the tumor. Encouraging results from preclinical studies predict that these findings will be translated into the clinical field in the near future.
\end{abstract}

\section{Introduction}

Glioblastomas account for the great majority of primary brain tumors in adults. Despite multimodality treatments, the prognosis remains poor, with a median survival time of approximately 1 year following the diagnosis of glioblastoma [1-4]. How can such an aggressive tumor arise in the brain, a carefully orchestrated organ, where cellular proliferation is barely needed to maintain function? Over the past two decades, genetic, cell biological, and animal modeling studies have led to a better understanding of the formation and progression of malignant glioblastomas. The origin of these tumors, however, is not fully understood.

While early data suggested that glioblastomas originate from normal glial cells, more recent data suggest they may in fact arise from neural stem cells or neural progenitors $[5,6]$. The cancer stem cell (CSC) hypothesis suggests that neoplastic clones are maintained exclusively by a rare fraction of cells with stemness properties [5]. Glioblastomas contain multipotent tumor stem cells that could be responsible for populating and repopulating tumors [7].

Even though there is no evidence showing that most brain cells undergo division during adult life, the idea of a "window of neoplastic vulnerability" implies that oncogenic events may occur in still-proliferating fetal cells [7]. According to this theory, since neuronal cells divide (and undergo oncogenic events) early during embryogenesis, neuronal tumors such as medulloblastomas occur mostly early in life. Glial tumors, however, are more common and arise later in life, because glial proliferation occurs later. 
The existence of CSCs has major therapeutic implications. These cells have been isolated and characterized as a heterogeneous population with unique features, giving them a key status in tumor survival. From a therapeutic standpoint, a critical issue is to identify and understand the physiology of the cell(s) responsible for tumor formation and recurrence. Therapies that do not ablate the tumor stem cells will be ineffective in eradicating the tumor. These stem cells may be transformed variants of normal neural progenitor cells, but the functional identity of these cells (i.e., stem cells or neural progenitor cells) remains controversial $[4,6,7]$.

The present review aims to describe the role of CSCs in the initiation and development of glioblastomas, as well as their involvement in therapy resistance. To this end, we first address the mechanisms beyond normal adult neurogenesis, and secondly, the biochemical and genetic processes that drive cells towards tumor formation.

\section{Adult Neurogenesis}

Stem cells are immature cells with the capacity for selfrenewal and differentiation. Multipotent neural stem cells (NSCs) have the ability to differentiate into neurons and glia (astrocytes and oligodendrocytes) [35-37]. The process of neurogenesis, which consists in the formation of new neurons from neural stem/progenitor cells, occurs in two major regions of the adult mammalian brain: in the subventricular zone of the lateral ventricles (SVZ) and in the subgranular layer of the hippocampal dentate gyrus (SGZ). In the adult central nervous system (CNS), these new neurons are integrated into the mature neuronal circuitry and take on various functions, thereby contributing to the structural and functional plasticity of the system $[38,39]$.

2.1. Subventricular Zone. The subventricular zone is the largest neurogenic region of the adult brain. In this region, the true physiological NSCs are a special type of astrocyte positive for glial fibrillary acidic protein (GFAP) and known as type B cells. These astrocytes divide asymmetrically at a low duplication rate, producing a cell resembling itself and another small rounded cell (i.e., type $\mathrm{C}$ cells). These type $\mathrm{C}$ cells duplicate at a high rate and are therefore called transit-amplifying cells (TACs). These rapidly dividing TACs produce neuroblasts or neural progenitors that form aggregate chains which migrate at high speeds from the SVZ toward the olfactory bulb $(\mathrm{OB})$ through the rostral migratory stream (RMS). Thereafter, these immature neurons differentiate mostly into granule neurons and a small proportion of them become periglomerular neurons. These two types of neurons are GABAergic, are functionally integrated into mature circuits of $\mathrm{OB}$, and are constantly replaced throughout life $[40,41]$.

2.2. Subgranular Zone in the Dentate Gyrus. Similarly to what occurs in the SVZ, granule neurons arise from NPCs in the subgranular zone of the hippocampal dentate gyrus. The NSCs of this region are also a subset of special astrocytes [42] that populate the border between the hilus and the granule cell layer [43]. When activated, these types of B cells give rise to TACs; after a limited number of cell divisions, these TACs generate neuroblasts (or immature neurons) and are committed to a particular neuronal lineage. The maturation of these cells generates granular neurons, which are then integrated into preexisting hippocampal circuits. These new granule neurons extend their axons toward the molecular layer, receive afferents from the entorhinal cortex, and project their axons (called mossy fibers) toward the CA3 region, synapsing with CA3 interneurons and pyramidal cells. These mossy fibers exhibit glutamatergic terminals, indicating the formation of excitatory synapses [44].

2.3. Regulation of Adult Neurogenesis. NSCs are regulated by the integration of intrinsic factors with extrinsic signals from the surrounding microenvironment, known as neurogenic niche. A niche can be defined as the limited and specialized anatomic compartment formed by cellular and acellular components that integrates local and systemic factors, supports maintenance and survival, and actively regulates the function and proliferation of these cells [45].

The process of neurogenesis depends on a complex cascade of molecular signaling pathways. The candidate pathways for regulating neuronal differentiation of adult NSCs include Notch [46], bone morphogenetic protein (BMP) [47], Wnt [38], and sonic hedgehog (Shh) [48].

Neurotrophic factors also play an important role in adult neurogenesis, as they can regulate various stages of neuronal development, including their complete maturation. Brainderived neurotrophic factor (BDNF) and neurotrophin-3 (NT-3) are considered powerful molecular mediators in synaptic and morphological plasticity [49]. BDNF can induce proliferation, survival, and neuronal differentiation, most likely by inducing the expressions of $\mathrm{Na}^{+}$and $\mathrm{K}^{+}$channels and the synaptic maturation of NPCs [50-52]. NT-3 has also been shown to influence neuronal survival, proliferation, and differentiation $[53,54]$. Other neurotrophic and growth factors have also been shown to regulate NSCs, for example, fibroblast growth factor 2 (FGF-2), epidermal growth factor (EGF), transforming growth factor (TGF), ciliary neurotrophic factor (CNTF), and vascular endothelial growth factor (VEGF). Studies in which these molecules were administered have reported an increase in cellular survival and proliferation rates [55].

\section{Gliogenesis}

As discussed above, adult neurogenesis triggers remodeling of the neuronal circuitry through the addition of new neurons; however, it has also been shown that when deregulated, NSCs and their progenitors can lead to the formation of certain types of brain tumors, including glioblastoma multiforme (GBM).

Brain tumors are composed of different cell populations differing in phenotype and functional features. Most of the cells that make up the tumor mass appear to be nontumorigenic, and only a small subpopulation of cells (i.e., cancer stem cells (CSCs)) is responsible for tumor initiation and recurrence [56]. The presence of CSCs in brain tumors was 
first reported following the isolation of clonogenic stem celllike spheres from human GBM tissue [57].

There are several theories regarding the origin of CSCs. One hypothesis is based on the idea that CSCs are derived from physiological stem cells that acquire the ability to generate tumors following genetic mutations or environmental alterations. This can occur because physiological stem cells have a long life expectancy and divide frequently, which makes them more susceptible to becoming tumorigenic [58]. The B type cells of the SVZ and SGZ are normally in a quiescent state and proliferate rapidly when necessary. One of the stages that is most susceptible to cell transformation is the transition of NSCs into TACs, because it involves a rearrangement in chromatin and rapid proliferation. Thus, if a genetic lesion is not fixed and remains within that cell, it becomes incorporated into the dividing cells, increasing the risk of other injuries and, consequently, giving rise to a cancerous cell $[4,59]$.

Glioma stem-like cells (GSCs) have many properties similar to those of NSCs, such as the capacity for self-renewal, proliferation, migration, and differentiation into at least one specific lineage. Also, they express common sets of markers and share signaling pathways responsible for proliferation $[38,56]$.

CD133 is a transmembrane glycoprotein that is normally expressed by neural stem cells, endothelial precursor cells, and hematopoietic stem cells [60-62] and has become a distinctive marker of GSCs. CD133 levels are highly correlated with cells' clonogenicity, as shown by in vitro models; this has led some to hypothesize that glioblastomas are derived from $\mathrm{CD}_{133^{+}}$cells, but it is well known that some glioblastomas are $\mathrm{CD}_{133^{-}}[5,6,20,63-65]$. Some studies have shown that these cells do not differ in gene expression or long-term survival rates and that they may even coexist in glioblastomas [66,67]. High levels of $\mathrm{CD} 133^{+}$have been associated with progression and survival (independently of tumor grade, the extent of resection, or the patient's age) as well as with tumor regrowth and a high risk of dissemination. In $\mathrm{CD} 133^{-}$cells, on the other hand, investigators have been able to use CD15 as a GSCs marker [68-70].

In recent studies, it was shown that glioblastomas can exhibit different phenotypes and cell clones with distinct tumorigenic potential. In other words, the heterogeneity of tumors may be responsible for therapy resistance, migratory pattern, tumor invasion, proliferation, chemoresistance, tumor maintenance, self-renewal characteristics, tumor initiation, and oncogenic potential. Several studies have identified CD44, CD155, EGFR, L1CAM, A2B5, and integrin A6 as being responsible for the development of these characteristics. This highlights the need for studies that can identify distinct patterns of superficial markers that will distinguish GSCs to an efficient target therapy [8-12, 32-34, 71, 72].

Once the neurogenic niches house the NSCs (cells with a relatively large chance of becoming cancerous cells) and support the maintenance, survival and proliferation of these cells, they become the most vulnerable sites for growth and proliferation of transformed cells. Given that the SVZ is the largest neurogenic niche, it is believed that this region gives rise to the highest number of glioblastomas. However,
GSCs and their progeny are not restricted to neurogenic niches; they can migrate away from their place of origin, as demonstrated by the presence of tumors in other brain regions.

Despite the consistent body of evidence supporting NSCs as cells that give rise to gliomas, the possibility that these tumors arise from a fully differentiated cell type, such as a mature glial cell, has not been excluded [6, 73] (Figure 1). Astrocytoma mouse models have used combinations of oncogenic overexpression and/or tumor suppressor inactivation to induce tumor formation [74, 75], and some of these models have not been limited to NSCs.

To investigate the increased invasiveness of gliomas with Rictor mTORC2 signaling pathway overexpression, Bashir and colleagues [76] inserted human Rictor transgene strains into mice. This Rictor strain was crossed with mice expressing a recombinase limited to the glial compartment (astrocytes and oligodendrocytes) and resulted in the formation of multifocal intermediate and low-grade gliomas. In another recent study, transduced mature astrocytes with loss of p53 and oncogene overexpression simulated pivotal features of glioma pathogenesis [77]. These data obviously contradict the notion that gliogenesis arises solely from NSCs and adds fuel to the ongoing debate: is gliomagenesis a stem cell disorder or a reacquisition of stem cell characteristics?

\section{Perivascular Niche}

GSCs are found in a microenvironment that is very similar to that of normal stem cells. This microenvironment provides an ideal condition for tumor maintenance; however, it does not have the structural organization and stability generally associated with stem cell niches, and it also cannot be defined by a single location [78]. The tumor perivascular niche (PVN) is composed of a heterogenous group of cell types, including astrocytes, endothelial cells, macrophages, microglia, nontumor initiating cells, and brain tumor stemlike cells [79].

Tumors require a large amount of nutrients and oxygen to support their rapid growth, which occurs mostly during angiogenesis. This is often observed in cases of more aggressive brain tumors with large angiogenic activity, including endothelial hyperplasia and microvascular proliferation [80]. The vascular niches in brain tumors are abnormal and contribute directly to the generation of GSCs and tumor growth. Moreover, these niches protect the GSCs from environmental aggression and, in the process, provide resistance to conventional therapies [81]. Furthermore, there is a reciprocity between GSCs and their microenvironment: GSCs are capable of modulating their own microenvironment to produce signals to recruit other immature cells in the vicinity. One example is VEGFs secreted by GSCs, which are able to stimulate the growth of endothelial cells that support the local vascular environment $[4,82]$.

\section{The Hypoxic Microenvironment}

Hypoxia in the microenvironment is a characteristic of malignant tumors. In GBM patients, hypoxia is associated with 
Tumorigenesis
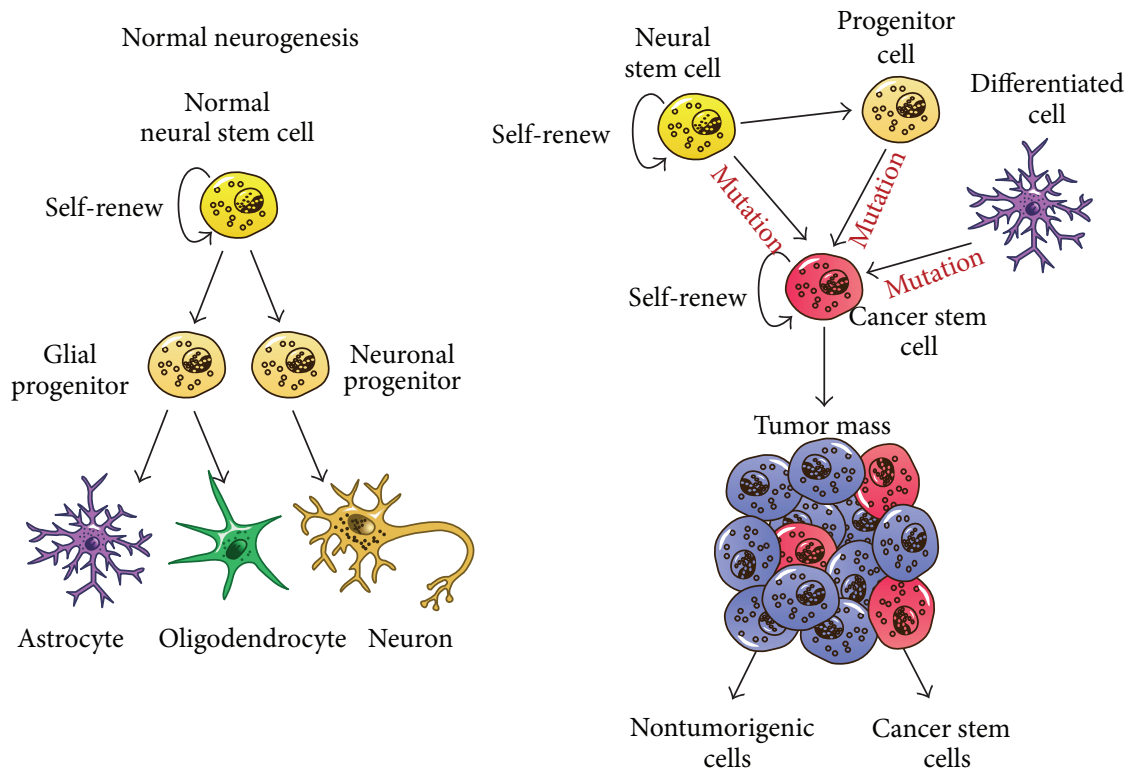

FIGURE 1: Cancer stem cell hypothesis. On the left, normal NSCs of the adult organism undergo extensive self-renewing division and give rise to a progenitor cell that differentiates into the three main neural lineages: neurons, astrocytes, and oligodendrocytes. On the right, CSCs are derived from physiological NSCs, progenitor cells, or mature brain cell, which acquire the ability to generate tumors following genetic mutations. The tumor mass is composed by different cell populations. Most of these cells appear to be nontumorigenic and only a small subpopulation of them represent the CSCs.

tumor aggression and a negative prognosis [83]. Vascularization acts as a neoplastic feeding source and, due to the rapid tumor expansion, the vessels are often disorganized and unable to adequately deliver oxygen [84]. When the vasculature irrigates inefficiently, the low oxygen tension induces neovascularization in order to meet the tissue's needs $[85,86]$.

These cellular responses to hypoxia are commonly regulated by the transcription factor system of the hypoxiainducible factors (HIFs) [87]. HIFs are heterodimers composed of an oxygen-sensitive HIF $\alpha$ subunit and a constitutively expressed HIF $\beta$ subunit. Under normal oxygen conditions, HIFl $\alpha$ binds to the tumor suppressor protein von Hippel-Lindau (vHL); this interaction ubiquitinates and targets the HIF $\alpha$ to the proteasome, where it is degraded. Under conditions of hypoxia, however, the interaction between $\mathrm{HIF} \alpha$ and vHL is abrogated; as a consequence, $\mathrm{HIF} \alpha$ becomes stabilized, leading to dimerization. It then binds to hypoxiaresponsive elements (HREs) on the promoters of target genes that are often involved in modulating cell survival, motility, and metabolism $[88,89]$. The activation of HIF $\alpha$ also plays a regulatory role in the expression of VEGF and inducible nitric oxide synthase (iNOS), facilitating angiogenesis and the tumor cell's access to the circulatory system [90]. Two HIF $\alpha$ subunits, HIF- $1 \alpha$ and HIF- $2 \alpha$, are primarily responsible for regulating the tumor's adaptation to hypoxia. HIF- $1 \alpha$ and HIF- $2 \alpha$ are structurally similar in their DNA binding and dimerization domains; however, they can play nonoverlapping roles in tumor progression due to their unique target genes and different oxygen requirements for activation [85, $89,91]$.
HIF- $1 \alpha$ is widely expressed in several tissues, including normal neural progenitors, and is able to regulate cancer stem cell proliferation and survival. On the other hand, HIF- $2 \alpha$ shows a more restricted expression pattern and is associated with cancer initiation or tumor progression, making it an attractive therapeutic target [89]. Interestingly, it has been shown that HIF- $2 \alpha$ is able to promote a more stem-like phenotype in nonstem cancer cells, upregulating some key stem cell factors such as Oct4, Nanog, and c-Myc [92].

Several studies have demonstrated the importance of hypoxia and HIF in tumor biology and in the maintenance of GSCs, as well as their role in chemotherapy and radiotherapy resistance. Despite progress in recent years, a better understanding of this process is still needed for the development of new therapeutic strategies.

\section{GSC Signaling Pathways}

Signaling pathways can play a crucial role in the biology of physiological stem cells. When several of these pathways are dysregulated, they can lead to tumor initiation, progression, and metastasis. Some examples of these are Notch, bone morphogenetic protein (BMP), Wnt/ $\beta$-catenin, sonic hedgehog (Shh), and STAT3.

Notch receptors are involved in several biological functions, including cell proliferation, differentiation, survival, and tumorigenesis [13]. Signaling by the Notch receptor occurs via cell-cell contact. Four Notch genes (Notch 1 to 4 ) have been identified in mammals, which act as transmembrane receptors for the Jagged (Jag1-2) and Delta-like (Dll1, 
$3,4)$ ligands. When the pathway is activated, the receptor is cleaved and its intracellular region is translocated to the nucleus, acting as a transcription factor in conjunction with the CBF-1 (C promoter binding factor-1) protein. This is followed by the expression of transcriptional repressor genes such as Hes1 and Hes5, which repress the expression of proneural genes, thereby inhibiting neuronal differentiation. Thus, when activated, Notch signaling leads to the maintenance of the NSC population, while its inactivation induces neuronal differentiation [46]. It has been reported that Notch signaling is upregulated in GSCs, leading to uncontrolled selfrenewal patterns [56, 93]. Moreover, Notch pathways have been shown to promote therapy resistance. Blocking Notch pathways depletes CD133-positive glioblastoma cells, thus decreasing tumor sphere formation, GCS proliferation, and xenograft growth and increasing differentiation [21].

In parallel, BMPs are a family of cytokines that regulate the proliferation, apoptosis, and differentiation of NSCs; this signaling process is a potent inhibitor of neurogenesis, blocking the production of neurons by inducing adult NPCs to adopt a glial fate [94]. The BMPs also act in GSCs, promoting astrocyte-like differentiation and inhibiting cellular proliferation [30]. BMP4 inhibits GSC proliferation via the downregulation of cyclin D1 and induces apoptosis by inducing Bax expression and inhibiting Bcl-2 and Bcl-xL [95]. Experimental studies have shown that the treatment of cultured GSCs with BMPs reduces the size of the tumors grafted into mice and prolongs the animals' survival [96].

Another candidate pathway able to regulate neuronal differentiation of adult NSCs and modulate GSC self-renewal is the $\mathrm{Wnt} / \beta$-catenin signaling pathway [38]. In the Wnt pathway, the signal is transmitted from the surface to the nucleus through the $\beta$-catenin protein. In the absence of signal, a complex of proteins containing glycogen synthase kinase $3 \beta$ (GSK3 $\beta$ ) phosphorylates the cytoplasmic $\beta$-catenin, which is then degraded by proteasomes. When the Wnt signal is activated, the activity of GSK3 $\beta$ is inhibited, resulting in the accumulation of $\beta$-catenin. The accumulated $\beta$-catenin translocates to the nucleus and induces the expression of growth-related genes $[97,98]$. Alterations in the Wnt pathway of glioblastomas lead to a negative prognosis. A selective inhibition of the Wnt signaling pathway in GSCs decreases cell proliferation, migration, and chemoresistance [22].

Other lines of evidence suggest that an altered Shh signaling pathway (generally associated with adult neurogenesis [48]) may lead to different types of cancer (solid and nonsolid) and is also associated with tumor development, proliferation, tumorigenesis, and metastasis $[14,15]$. Shh is an important morphogen that is secreted at various stages of development. The binding of Shh to its receptor Ptch (patched) relieves Smo (Smoothened) inhibition, which in turn leads to the transcription of proteins from the Gli family (transcription factor). This Shh/Gli signaling pathway is necessary for CSC proliferation, self-renewal, and survival $[14,15]$. Treatment of GSCs-derived neurospheres with the Hedgehog inhibitor cyclopamine inhibits CSC proliferation and self-renewal [99].

Finally, STAT3 (a member of the STAT family of cytoplasmic transcription factors) has been implicated in NSC development [100] and also in the formation of many types of tumors, including GBM [101]. STAT3 is activated by many cytokine and growth factor receptors. When activated, STAT3 enters the nucleus and triggers the gene expression of many procancerous proteins associated with cell cycle progression, antiapoptosis, angiogenesis, migration, and invasion [31]. Treating GSCs with small molecules that inhibit STAT3 DNA-binding has been shown to inhibit cell proliferation and the formation of new neurospheres from single cells [23]. Moreover, the inhibition of STAT3 also decreases the expressions of CD133 and c-Myc in GSCs and leads to apoptotic cell death [102].

\section{Transcription Factors}

Just like the signaling pathways, transcription factors play an important role in the maintenance and regulation of tumor cells. These factors are directly involved in the survival, maintenance, proliferation, and self-renewal of GSCs. Investigators have indicated that the transcription factors that play a significant role in brain tumors include Bmil, Olig2, c-Myc, Sox2, Oct4, and Nanog.

Authors agree that some transcription factors play an important role in inducing tumor cells to act like stem cells. This suggests that even a small error during neurogenesis can initiate a cascade of reactions that may result in the formation of a glioblastoma.

Belonging to the family of Polycomb group proteins (which play the role of epigenetic regulators during the embryonic period), the Bmil is a component of the Polycomb Repressive Complex 1 (PRC1) found in undifferentiated neural stem cells. The PRCl supports the maintenance of neural stem cell function and contains tumor-suppressor mechanisms. When cancer cells silence these mechanisms, there is a reduction in the amount of normal neural stem cells and a delay in the process of gliogenesis [103]. A significant link has been found between the manifestation of an aggressive phenotype of glioblastomas and high levels of Bmil, as this seems to activate the nuclear factor kappaB (NF-kappaB). This factor is also activated in several other cancers and results in the increased regulation and activation of matrix metalloproteinase-9 (MMP-9), which is responsible for the destruction of extracellular matrix and basal membranes [104]. However, some studies suggest that such high values of Bmil in several tumors are the result of other mutations: when tested in in vivo transgenic mice models (compared to in vitro models), Bmil was observed to have a low proliferative effect, a low effect on fetal and adult neurogenesis, and a low effect on glial differentiation. Furthermore, it did not result in an increased capacity for self-renewal and neurogenic potential [105].

Recent studies have demonstrated that gene silencing of Bmil, for example, by MicroRNA-218 (miR-218), MicroRNA128 (miR-128), or epigenetic regulation of Survivin, results in decreased rates of tumor cell invasion, migration, proliferation, and self-renewal. Furthermore, the absence of these factors leads to gliogenesis, and some of these mechanisms are essential for normal and neoplastic cells to survive following Bmil-induced proliferation [24-26]. 
TABLE 1: Main mechanisms involved with GSCs.

\begin{tabular}{|c|c|c|c|}
\hline \multicolumn{4}{|c|}{ Glioma stem cells } \\
\hline Main features & Surface markers & Signaling pathways & Transcription factors \\
\hline Tumorigenesis & $\begin{array}{c}\text { L1CAM [8], EGFR [9], } \\
\text { IntegrinA6 [10], CD155 [11], } \\
\text { A2B5 [12] }\end{array}$ & Notch $[13]$, Shh $[14,15]$ & $\begin{array}{c}\text { Olig2 [16], Oct4 [17], Sox2 [17], } \\
\text { Nanog }[18,19]\end{array}$ \\
\hline $\begin{array}{l}\text { Self- } \\
\text { renewal/proliferation }\end{array}$ & $\begin{array}{l}\text { EGFR [9], CD133 [20], } \\
\text { IntegrinA6 [10] }\end{array}$ & $\begin{array}{c}\text { Notch }[21], \text { Shh }[14,15], \text { Wnt } \\
\text { [22], STAT3 [23] }\end{array}$ & $\begin{array}{c}\text { Bmil [24-26], Sox2 [27], Nanog } \\
\text { [18, 19], Olig2 [28], c-Myc [29] }\end{array}$ \\
\hline Differentiation & - & $\mathrm{BMP}[30]$ & - \\
\hline Survival & - & Shh $[14,15]$, STAT3 [31] & Bmil [24-26], c-Myc [29] \\
\hline $\begin{array}{l}\text { Migratory } \\
\text { pattern/metastasis }\end{array}$ & CD44 [32], CD155 [11] & Wnt [22], Shh $[14,15]$, STAT3 [31] & Bmil [24-26] \\
\hline Tumor invasion & CD44 [33], CD155 [11] & STAT3 [31] & Bmil [24-26] \\
\hline Therapy resistance & L1CAM [34] & Notch [21], Wnt [22] & - \\
\hline
\end{tabular}

This table lists the markers, signaling pathways, and transcription factors related to specific features of GSCs.

Olig2 plays an important role in CNS development during the embryonic phase as well as in malignant glioblastomas during adulthood (for a detailed review, see [106]). Olig2's triple serine phosphorylation regulates the suppressive action of $\mathrm{p} 53$, which triggers proliferation in normal and malignant neural progenitors. However, this state of phosphorylation does not seem related to the specification and terminal differentiation of oligodendrocytes $[107,108]$. Some possible transcripts involved in the promotion of quiescence and the differentiation state in Olig2 tumor cells seem to be deleted during tumorigenesis. Glioblastoma cells share characteristics with oligodendroglial progenitor cells, such as the fact that tumorigenesis is initiated by a glial progenitor-like cell [109]. Appolloni et al. showed that when Olig2 is silenced (or when this effect is mimicked by high levels of other factors, e.g., Pax6 or ID4), tumorigenesis and tumor growth are considerably reduced [28].

c-Myc, Oct4, and Sox2 (alongside Klf4) are used to reprogram embryonic and adult cells to induce pluripotency [16]. These factors are also associated with high-grade glioblastomas, promoting tumorigenic activity, glioma stem cell self-renewal, neurosphere formation, glioma stem cell proliferation, and in some cases-like c-Myc-acting as a GSC-specific survival factor [17-19, 27, 29, 110-113]. Glioma stem cells express high levels of c-Myc, and their proliferation and cell cycle progression are also regulated by c-Myc (see Table 1). The loss of this oncogenic factor induces GSC apoptosis and reduces neurosphere formation, while the knockdown of c-Myc inhibits GSCs' tumorigenic potential [29]. In a recent study, Elsir et al. studied the correlation between Nanog, c-Myc, Oct4, Sox2, and Klf4 in high-grade glioblastomas, low-grade glioblastomas, and low-grade astrocytomas. They observed the expressions of Oct4, Sox2, and Nanog in more than $50 \%$ of tumor cells and showed a possible correlation between these proteins in the regulation of the pluripotency and self-renewal of GSCs. The main finding in this work was a possible regulatory pathway of these proteins in glioblastomas. This makes them safe biomarkers for future clinical approaches and deems Nanog a determining factor in the clinical outcome [114].
As described above, many transcription factors seem to be involved in the stem cell-like state of tumor cells. It is likely that the combined effects of these transcription factors are the main reason why it is so difficult to establish a promising treatment. Exactly how these factors promote tumorigenesis is yet to be clarified, but recent findings have shed a light on our understanding of the mechanisms underlying tumor cells.

\section{Radioresistance and Chemoresistance}

There are several hypotheses regarding the mechanisms of radio and chemoresistance. In terms of radioresistance, the influence of different signaling pathways seems to give GSCs the ability to repair DNA more rapidly and efficiently than normal cells. Polycomb group proteins (e.g., Bmil) also influence DNA repair and when they are deficient, GSCs are sensitized to radiation. The autophagy system, the notch pathway, the Akt signaling, and Wnt proteins all seem to contribute to the resistance of GSCs to radiotherapy, and some of these mechanisms affect both tumor cells and normal stem cells. In terms of chemoresistance, some theories implicate $\mathrm{ABC}$ drug transporters, which are regulated by Akt and are responsible for activating the efflux of various substrates across extra- and intracellular membranes; the participation of CD133 cell markers and the notch and shh signaling pathways that interact with DNA repair machinery have also been implicated. For a thorough review of this issue, see [115].

More studies need to be conducted to better understand the specific mechanisms underlying drug and radiation resistance, as well as how these mechanisms operate to make GSCs resistant to these clinical approaches. One great challenge to establishing a target therapy is that various mechanisms involved in brain tumors are basically the same mechanisms recruited in neurogenesis, which raises the following questions: how far can we go with an efficient target therapy without compromising normal cells? How can we eliminate a tumor without eliminating the normal stem cells that are necessary for recovering damaged areas? 
Clearly, there is a great need for studies that can identify the heterogeneous phenotype in GSCs in order to identify efficient target therapies.

\section{Conclusion}

Glioblastoma multiforme is one of the most aggressive forms of brain tumor and is associated with poor outcome and low survival rates. Despite all the current available treatments, surgery continues to be the most efficient option, although it has not been associated with high rates of improvement. Recent studies have focused on the main factors that initiate gliogenesis. Several hypotheses aim to describe the mechanisms involved in a normal cell's transformation into a malignant cell. Problems with signaling pathways or transcription factors-as well as other minor errors that may occur during neurogenesis-have been shown to guide neural stem cells toward a malignant phenotype. However, the greatest difficulty lies in the fact that these mechanisms are shared between normal cells and tumor cells.

These shared mechanisms are highly important for normal cell growth, proliferation, self-renewal, and differentiation, but they are also important for tumor cell survival and proliferation. Knowledge about malignant tumors allows us to better understand the behavior of malignant cells and to unveil the mechanisms that initiate tumorigenesis. This would represent an important starting point towards winning the battle against cancer.

\section{Conflict of Interests}

The authors declare that there is no conflict of interests regarding the publication of this paper.

\section{References}

[1] T. Shahar, E. Nossek, D. M. Steinberg et al., "The impact of enrollment in clinical trials on survival of patients with glioblastoma," Journal of Clinical Neuroscience, vol. 19, no. 11, pp. 1530-1534, 2012.

[2] M. J. McGirt, K. L. Chaichana, F. J. Attenello et al., "Extent of surgical resection is independently associated with survival in patients with hemispheric infiltrating low-grade gliomas," Neurosurgery, vol. 63, no. 4, pp. 700-708, 2008.

[3] E. R. Laws, I. F. Parney, W. Huang et al., "Survival following surgery and prognostic factors for recently diagnosed malignant glioma: data from the glioma outcomes project," Journal of Neurosurgery, vol. 99, no. 3, pp. 467-473, 2003.

[4] F. D. A. Sassi, A. L. Brunetto, G. Schwartsmann, R. Roesler, and A. L. Abujamra, "Glioma revisited: from neurogenesis and cancer stem cells to the epigenetic regulation of the niche," Journal of Oncology, vol. 2012, Article ID 537861, 20 pages, 2012.

[5] S. K. Singh, C. Hawkins, I. D. Clarke et al., "Identification of human brain tumour initiating cells," Nature, vol. 432, no. 7015, pp. 396-401, 2004.

[6] R. Galli, E. Binda, U. Orfanelli et al., "Isolation and characterization of tumorigenic, stem-like neural precursors from human glioblastoma," Cancer Research, vol. 64, no. 19, pp. 7011-7021, 2004 .
[7] D. N. Louis, "Molecular pathology of malignant gliomas," Annual Review of Pathology, vol. 1, no. 1, pp. 97-117, 2006.

[8] L. Cheng, Q. Wu, O. A. Guryanova et al., "Elevated invasive potential of glioblastoma stem cells," Biochemical and Biophysical Research Communications, vol. 406, no. 4, pp. 643-648, 2011.

[9] D. R. Emlet, P. Gupta, M. Holgado-Madruga et al., "Targeting a glioblastoma cancer stem cell population defined by EGF receptor variant III," Cancer Research, 2013.

[10] J. D. Lathia, J. Gallagher, J. M. Heddleston et al., "Integrin Alpha 6 regulates glioblastoma stem cells," Cell Stem Cell, vol. 6, no. 5, pp. 421-432, 2010.

[11] K. E. Sloan, B. K. Eustace, J. K. Stewart et al., "CD155/PVR plays a key role in cell motility during tumor cell invasion and migration," BMC Cancer, vol. 4, article 73, 2004.

[12] A. Tchoghandjian, N. Baeza, C. Colin et al., "A2B5 cells from human glioblastoma have cancer stem cell properties," Brain Pathology, vol. 20, no. 1, pp. 211-221, 2010.

[13] F. Radtke and K. Raj, "The role of Notch in tumorigenesis: oncogene or tumour suppressor," Nature Reviews Cancer, vol. 3, no. 10, pp. 756-767, 2003.

[14] L. A. Milla, C. N. Gonzalez-Ramirez, and V. Palma, "Sonic Hedgehog in cancer stem cells: a novel link with autophagy," Biological Research, vol. 45, no. 3, pp. 223-230, 2013.

[15] N. Dahmane, P. Sánchez, Y. Gitton et al., "The Sonic HedgehogGli pathway regulates dorsal brain growth and tumorigenesis," Development, vol. 128, no. 24, pp. 5201-5212, 2001.

[16] K. Takahashi and S. Yamanaka, "Induction of pluripotent stem cells from mouse embryonic and adult fibroblast cultures by defined factors," Cell, vol. 126, no. 4, pp. 663-676, 2006.

[17] H. Ikushima, T. Todo, Y. Ino et al., "Glioma-initiating cells retain their tumorigenicity through integration of the Sox axis and Oct4 protein," Journal of Biological Chemistry, vol. 286, no. 48, pp. 41434-41441, 2011.

[18] A. Sato, M. Okada, K. Shibuya et al., "Resveratrol promotes proteasome-dependent degradation of Nanog via p53 activation and induces differentiation of glioma stem cells," Stem Cell Research, vol. 11, no. 1, pp. 601-610, 2013.

[19] M. Zbinden, A. Duquet, A. Lorente-Trigos, S.-N. Ngwabyt, I. Borges, and A. Ruiz i Altaba, "NANOG regulates glioma stem cells and is essential in vivo acting in a cross-functional network with GLI1 and p53," The EMBO Journal, vol. 29, no. 15, pp. 26592674, 2010.

[20] D. Beier, P. Hau, M. Proescholdt et al., "CD133+ and CD133glioblastoma-derived cancer stem cells show differential growth characteristics and molecular profiles," Cancer Research, vol. 67, no. 9, pp. 4010-4015, 2007.

[21] X. Fan, L. Khaki, T. S. Zhu et al., "NOTCH pathway blockade depletes CD133-positive glioblastoma cells and inhibits growth of tumor neurospheres and xenografts," Stem Cells, vol. 28, no. 1, pp. 5-16, 2010.

[22] N. Kaur, S. Chettiar, S. Rathod et al., "Wnt3a mediated activation of Wnt/ $\beta$-catenin signaling promotes tumor progression in glioblastoma," Molecular and Cellular Neuroscience, vol. 54, pp. 44-57, 2013.

[23] M. M. Sherry, A. Reeves, J. K. Wu, and B. H. Cochran, "STAT3 is required for proliferation and maintenance of multipotency in glioblastoma stem cells," Stem Cells, vol. 27, no. 10, pp. 23832392, 2009.

[24] S. Acquati, A. Greco, D. Licastro et al., "Epigenetic regulation of survivin by Bmil is cell type specific during corticogenesis and in gliomas," Stem Cells, vol. 31, no. 1, pp. 190-202, 2013. 
[25] P. Peruzzi, A. Bronisz, M. O. Nowicki et al., "MicroRNA-128 coordinately targets Polycomb Repressor Complexes in glioma stem cells," Neuro-Oncology, vol. 15, no. 9, pp. 1212-1224, 2013.

[26] Y. Tu, X. Gao, G. Li et al., "MicroRNA-218 inhibits glioma invasion, migration, proliferation, and cancer stem-like cell selfrenewal by targeting the polycomb group gene Bmil," Cancer Research, vol. 73, no. 19, pp. 6046-6055, 2013.

[27] H.-M. Jeon, Y.-W. Sohn, S.-Y. Oh, S.-H. Kim, S. Beck, and S. Kim, "ID4 imparts chemoresistance and cancer stemness to glioma cells by derepressing miR-9* -mediated suppression of SOX2," Cancer Research, vol. 71, no. 9, pp. 3410-3421, 2011.

[28] I. Appolloni, F. Calzolari, M. Barilari, M. Terrile, A. Daga, and P. Malatesta, "Antagonistic modulation of gliomagenesis by Pax6 and Olig2 in PDGF-induced oligodendroglioma," International Journal of Cancer, vol. 131, no. 7, pp. E1078-E1087, 2012.

[29] J. Wang, H. Wang, Z. Li et al., "c-Myc is required for maintenance of glioma cancer stem cells," PLoS ONE, vol. 3, no. 11, Article ID e3769, 2008.

[30] J. Lee, M. J. Son, K. Woolard et al., "Epigenetic-mediated dysfunction of the bone morphogenetic protein pathway inhibits differentiation of glioblastoma-initiating cells," Cancer Cell, vol. 13, no. 1, pp. 69-80, 2008.

[31] R. B. Luwor, S. S. Stylli, and A. H. Kaye, "The role of Stat3 in glioblastoma multiforme," Journal of Clinical Neuroscience, vol. 20, no. 7, pp. 907-911, 2013.

[32] L. V. DeSouza, A. Matta, Z. Karim et al., "Role of moesin in hyaluronan induced cell migration in glioblastoma multiforme," Molecular Cancer, vol. 12, article 74, 2013.

[33] Z. Maherally, J. R. Smith, Q. An, and G. J. Pilkington, "Receptors for hyaluronic acid and poliovirus: a combinatorial role in glioma invasion?” PLoS ONE, vol. 7, no. 2, Article ID e30691, 2012.

[34] J. Held-Feindt, S. Schmelz, K. Hattermann, R. Mentlein, H. M. Mehdorn, and S. Sebens, "The neural adhesion molecule L1CAM confers chemoresistance in human glioblastomas," Neurochemistry International, vol. 61, no. 7, pp. 1183-1191, 2012.

[35] J. Li and G. Lepski, "Cell transplantation for spinal cord injury: a systematic review," BioMed Research International, vol. 2013, Article ID 786475, 32 pages, 2013.

[36] N. L. Kennea and H. Mehmet, "Neural stem cells," The Journal of Pathology, vol. 197, no. 4, pp. 536-550, 2002.

[37] M. Hosseinkhani, R. Shirazi, F. Rajaei, M. Mahmoudi, N. Mohammadi, and M. Abbasi, "Engineering of the embryonic and adult stem cell niches," Iranian Red Crescent Medical Journal, vol. 15, no. 2, pp. 83-92, 2013.

[38] G.-L. Ming and H. Song, "Adult neurogenesis in the mammalian central nervous system," Annual Review of Neuroscience, vol. 28, no. 1, pp. 223-250, 2005.

[39] S. Fukuda, F. Kato, Y. Tozuka, M. Yamaguchi, Y. Miyamoto, and T. Hisatsune, "Two distinct subpopulations of nestin-positive cells in adult mouse dentate gyrus," The Journal of Neuroscience, vol. 23, no. 28, pp. 9357-9366, 2003.

[40] M. Sawada and K. Sawamoto, "Mechanisms of neurogenesis in the normal and injured adult brain," The Keio Journal of Medicine, vol. 62, no. 1, pp. 13-28, 2013.

[41] L. Petreanu and A. Alvarez-Buylla, "Maturation and death of adult-born olfactory bulb granule neurons: role of olfaction," The Journal of Neuroscience, vol. 22, no. 14, pp. 6106-6113, 2002.

[42] B. Seri, J. M. García-Verdugo, B. S. McEwen, and A. AlvarezBuylla, "Astrocytes give rise to new neurons in the adult mammalian hippocampus," The Journal of Neuroscience, vol. 21, no. 18 , pp. 7153-7160, 2001.
[43] F. H. Gage, "Mammalian neural stem cells," Science, vol. 287, no. 5457, pp. 1433-1438, 2000.

[44] Y. Ide, F. Fujiyama, K. Okamoto-Furuta, N. Tamamaki, T. Kaneko, and T. Hisatsune, "Rapid integration of young newborn dentate gyrus granule cells in the adult hippocampal circuitry," European Journal of Neuroscience, vol. 28, no. 12, pp. 2381-2392, 2008.

[45] A. D. Lander, J. Kimble, H. Clevers et al., "What does the concept of the stem cell niche really mean today?" BMC Biology, vol. 10, article 19, 2012.

[46] I. Imayoshi, M. Sakamoto, M. Yamaguchi, K. Mori, and R. Kageyama, "Essential roles of Notch signaling in maintenance of neural stem cells in developing and adult brains," The Journal of Neuroscience, vol. 30, no. 9, pp. 3489-3498, 2010.

[47] F. Doetsch, L. Petreanu, I. Caille, J.-M. Garcia-Verdugo, and A. Alvarez-Buylla, "EGF converts transit-amplifying neurogenic precursors in the adult brain into multipotent stem cells," Neuron, vol. 36, no. 6, pp. 1021-1034, 2002.

[48] V. Palam, D. A. Lim, N. Dahmane et al., "Sonic hedgehog controls stem cells behavior in the postnatal and adult brain," Development, vol. 132, no. 2, pp. 335-344, 2005.

[49] A. Gómez-Palacio-Schjetnan and M. L. Escobar, "Neurotrophins and synaptic plasticity," Current Topics in Behavioral Neurosciences, vol. 15, pp. 117-136, 2013.

[50] E. S. Levine, C. F. Dreyfus, I. B. Black, and M. R. Plummer, "Differential effects of NGF and BDNF on voltage-gated calcium currents in embryonic basal forebrain neurons," The Journal of Neuroscience, vol. 15, no. 4, pp. 3084-3091, 1995.

[51] J. Leng, L. Jiang, H. Chen, and X. Zhang, "Brain-derived neurotrophic factor and electrophysiological properties of voltagegated ion channels during neuronal stem cell development," Brain Research, vol. 1272, pp. 14-24, 2009.

[52] G. Lepski, C. E. Jannes, G. Nikkhah, and J. Bischofberger, "cAMP promotes the differentiation of neural progenitor cells in vitro via modulation of voltage-gated calcium channels," Frontiers Cellular Neuroscience, vol. 7, article 155, 2013.

[53] A. Ghosh and M. E. Greenberg, "Distinct roles for bFGF and NT-3 in the regulation of cortical neurogenesis," Neuron, vol. 15, no. 1, pp. 89-103, 1995.

[54] H.-X. Lu, Z.-M. Hao, Q. Jiao et al., "Neurotrophin-3 gene transduction of mouse neural stem cells promotes proliferation and neuronal differentiation in organotypic hippocampal slice cultures," Medical Science Monitor, vol. 17, no. 11, pp. BR305BR311, 2011.

[55] K. G. Bath and F. S. Lee, "Neurotrophic factor control of adult SVZ neurogenesis," Developmental Neurobiology, vol. 70, no. 5, pp. 339-349, 2010.

[56] K. Wang, X. Wu, J. Wang, and J. Huang, "Cancer stem cell theory: therapeutic implications for nanomedicine," International Journal of Nanomedicine, vol. 8, no. 1, pp. 899-908, 2013.

[57] T. N. Ignatova, V. G. Kukekov, E. D. Laywell, O. N. Suslov, F. D. Vrionis, and D. A. Steindler, "Human cortical glial tumors contain neural stem-like cells expressing astroglial and neuronal markers in vitro," Glia, vol. 39, no. 3, pp. 193-206, 2002.

[58] R. Gangemi, L. Paleari, A. M. Orengo et al., "Cancer stem cells: a new paradigm for understanding tumor growth and progression and drug resistance," Current Medicinal Chemistry, vol. 16, no. 14, pp. 1688-1703, 2009.

[59] F. A. Siebzehnrubl, B. A. Reynolds, A. Vescovi, D. A. Steindler, and L. P. Deleyrolle, "The origins of glioma: E Pluribus Unum?" Glia, vol. 59, no. 8, pp. 1135-1147, 2011. 
[60] P. Salven, S. Mustjoki, R. Alitalo, K. Alitalo, and S. Rafii, "VEGFR-3 and CD133 identify a population of CD34 $4^{+}$lymphatic/vascular endothelial precursor cells," Blood, vol. 101, no. 1, pp. 168-172, 2003.

[61] N. Uchida, D. W. Buck, D. He et al., "Direct isolation of human central nervous system stem cells," Proceedings of the National Academy of Sciences of the United States of America, vol. 97, no. 26, pp. 14720-14725, 2000.

[62] A. H. Yin, S. Miraglia, E. D. Zanjani et al., "AC133, a novel marker for human hematopoietic stem and progenitor cells," Blood, vol. 90, no. 12, pp. 5002-5012, 1997.

[63] S. Bao, Q. Wu, S. Sathornsumetee et al., "Stem cell-like glioma cells promote tumor angiogenesis through vascular endothelial growth factor," Cancer Research, vol. 66, no. 16, pp. 7843-7848, 2006.

[64] S. K. Singh, I. D. Clarke, T. Hide, and P. B. Dirks, "Cancer stem cells in nervous system tumors," Oncogene, vol. 23, no. 43, pp. 7267-7273, 2004.

[65] S. K. Singh, I. D. Clarke, M. Terasaki et al., "Identification of a cancer stem cell in human brain tumors," Cancer Research, vol. 63, no. 18, pp. 5821-5828, 2003.

[66] V. Clément, V. Dutoit, D. Marino, P.-Y. Dietrich, and I. Radovanovic, "Limits of CD133 as a marker of glioma selfrenewing cells," International Journal of Cancer, vol. 125, no. 1, pp. 244-248, 2009.

[67] K. M. Joo, S. Y. Kim, X. Jin et al., "Clinical and biological implications of CD133-positive and CD133-negative cells in glioblastomas," Laboratory Investigation, vol. 88, no. 8, pp. 808815, 2008.

[68] J. D. Lathia, M. Hitomi, J. Gallagher et al., "Distribution of CD133 reveals glioma stem cells self-renew through symmetric and asymmetric cell divisions," Cell Death \& Disease, vol. 2, no. 9, article e200, 2011.

[69] A. Sato, K. Sakurada, T. Kumabe et al., "Association of stem cell marker CD133 expression with dissemination of glioblastomas," Neurosurgical Review, vol. 33, no. 2, pp. 175-184, 2010.

[70] F. Zeppernick, R. Ahmadi, B. Campos et al., "Stem cell marker CD133 affects clinical outcome in glioma patients," Clinical Cancer Research, vol. 14, no. 1, pp. 123-129, 2008.

[71] I. Paul, S. Bhattacharya, A. Chatterjee, and M. K. Ghosh, "Current understanding on EGFR and Wnt/ $\beta$-catenin signaling in glioma and their possible crosstalk," Genes \& Cancer, vol. 4, no. 11-12, pp. 427-446, 2013.

[72] D. Stieber, A. Golebiewska, L. Evers et al., "Glioblastomas are composed of genetically divergent clones with distinct tumourigenic potential and variable stem cell-associated phenotypes," Acta Neuropathologica, vol. 127, no. 2, pp. 203-219, 2014.

[73] E. Passegué, C. H. M. Jamieson, L. E. Ailles, and I. L. Weissman, "Normal and leukemic hematopoiesis: are leukemias a stem cell disorder or a reacquisition of stem cell characteristics?" Proceedings of the National Academy of Sciences of the United States of America, vol. 100, supplement 1, pp. 11842-11849, 2003.

[74] S. A. Llaguno, J. Chen, C.-H. Kwon et al., "Malignant astrocytomas originate from neural stem/progenitor cells in a somatic tumor suppressor mouse model," Cancer Cell, vol. 15, no. 1, pp. 45-56, 2009.

[75] Y. Zhu, F. Guignard, D. Zhao et al., "Early inactivation of p53 tumor suppressor gene cooperating with NF1 loss induces malignant astrocytoma," Cancer Cell, vol. 8, no. 2, pp. 119-130, 2005.
[76] T. Bashir, C. Cloninger, N. Artinian et al., "Conditional astroglial Rictor overexpression induces malignant glioma in mice," PLoS ONE, vol. 7, no. 10, Article ID e47741, 2012.

[77] J. Radke, G. Bortolussi, and A. Pagenstecher, "Akt and c-Myc induce stem-cell markers in mature primary $\mathrm{p} 53^{-/-}$astrocytes and render these cells gliomagenic in the brain of immunocompetent mice," PLoS ONE, vol. 8, no. 2, Article ID e56691, 2013.

[78] A. Descot and T. Oskarsson, "The molecular composition of the metastatic niche," Experimental Cell Research, vol. 319, no. 11, pp. 1679-1686, 2013.

[79] N. A. Charles, E. C. Holland, R. Gilbertson, R. Glass, and H. Kettenmann, "The brain tumor microenvironment," Glia, vol. 60, no. 3, pp. 502-514, 2012.

[80] R. D. Folkerth, "Histologic measures of angiogenesis in human primary brain tumors," Cancer Treatment and Research, vol. 117, pp. 79-95, 2004.

[81] C. Calabrese, H. Poppleton, M. Kocak et al., "A perivascular niche for brain tumor stem cells," Cancer Cell, vol. 11, no. 1, pp. 69-82, 2007.

[82] J. D. Lathia, J. M. Heddleston, M. Venere, and J. N. Rich, "Deadly teamwork: neural cancer stem cells and the tumor microenvironment," Cell Stem Cell, vol. 8, no. 5, pp. 482-485, 2011.

[83] S. M. Evans, K. W. Jenkins, H. I. Chen et al., "The relationship among hypoxia, proliferation, and outcome in patients with de nouo glioblastoma: a pilot study," Translational Oncology, vol. 3, no. 3, pp. 160-169, 2010.

[84] P. Carmeliet and R. K. Jain, "Angiogenesis in cancer and other diseases," Nature, vol. 407, no. 6801, pp. 249-257, 2000.

[85] S. Seidel, B. K. Garvalov, V. Wirta et al., "A hypoxic niche regulates glioblastoma stem cells through hypoxia inducible

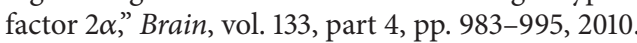

[86] D. Shweiki, A. Itin, D. Soffer, and E. Keshet, "Vascular endothelial growth factor induced by hypoxia may mediate hypoxiainitiated angiogenesis," Nature, vol. 359, no. 6398, pp. 843-845, 1992.

[87] B. Keith and M. C. Simon, "Hypoxia-inducible factors, stem cells, and cancer," Cell, vol. 129, no. 3, pp. 465-472, 2007.

[88] A. L. Harris, "Hypoxia-a key regulatory factor in tumour growth," Nature Reviews Cancer, vol. 2, no. 1, pp. 38-47, 2002.

[89] Z. Li, S. Bao, Q. Wu et al., "Hypoxia-inducible factors regulate tumorigenic capacity of glioma stem cells," Cancer Cell, vol. 15, no. 6, pp. 501-513, 2009.

[90] C. Branco-Price, N. Zhang, M. Schnelle et al., "Endothelial cell HIF- $1 \alpha$ and HIF- $2 \alpha$ differentially regulate metastatic success," Cancer Cell, vol. 21, no. 1, pp. 52-65, 2012.

[91] L. Holmquist-Mengelbier, E. Fredlund, T. Löfstedt et al., "Recruitment of HIF- $1 \alpha$ and HIF- $2 \alpha$ to common target genes is differentially regulated in neuroblastoma: HIF- $2 \alpha$ promotes an aggressive phenotype," Cancer Cell, vol. 10, no. 5, pp. 413-423, 2006.

[92] J. M. Heddleston, Z. Li, R. E. McLendon, A. B. Hjelmeland, and J. N. Rich, "The hypoxic microenvironment maintains glioblastoma stem cells and promotes reprogramming towards a cancer stem cell phenotype," Cell Cycle, vol. 8, no. 20, pp. 3274-3284, 2009.

[93] A. Bigas, J. Guiu, and L. Gama-Norton, "Notch and Wnt signaling in the emergence of hematopoietic stem cells," Blood Cells, Molecules, and Diseases, vol. 51, no. 4, pp. 264-270, 2013.

[94] D. A. Lim, A. D. Tramontin, J. M. Trevejo, D. G. Herrera, J. M. García-Verdugo, and A. Alvarez-Buylla, "Noggin antagonizes 
BMP signaling to create a niche for adult neurogenesis,' Neuron, vol. 28, no. 3, pp. 713-726, 2000.

[95] Z. Zhou, L. Sun, Y. Wang et al., "Bone morphogenetic protein 4 inhibits cell proliferation and induces apoptosis in glioma stem cells," Cancer Biotherapy \& Radiopharmaceuticals, vol. 26, no. 1, pp. 77-83, 2011.

[96] S. G. M. Piccirillo, B. A. Reynolds, N. Zanetti et al., "Bone morphogenetic proteins inhibit the tumorigenic potential of human brain tumour-initiating cells," Nature, vol. 444, no. 7120, pp. 761-765, 2006.

[97] N. Kawaguchi-Ihara, I. Murohashi, N. Nara, and S. Tohda, "Promotion of the self-renewal capacity of human acute leukemia cells by Wnt3A," Anticancer Research A, vol. 28, no. 5, pp. 27012704, 2008.

[98] T. Reya and H. Clevers, "Wnt signalling in stem cells and cancer," Nature, vol. 434, no. 7035, pp. 843-850, 2005.

[99] E. E. Bar, A. Chaudhry, A. Lin et al., "Cyclopamine-mediated Hedgehog pathway inhibition depletes stem-like cancer cells in glioblastoma," Stem Cells, vol. 25, no. 10, pp. 2524-2533, 2007.

[100] N. de la Iglesia, G. Konopka, S. V. Puram et al., "Identification of a PTEN-regulated STAT3 brain tumor suppressor pathway," Genes \& Development, vol. 22, no. 4, pp. 449-462, 2008.

[101] J. Bromberg, "Stat proteins and oncogenesis," The Journal of Clinical Investigation, vol. 109, no. 9, pp. 1139-1142, 2002.

[102] K. Sai, S. Wang, V. Balasubramaniyan et al., "Induction of cellcycle arrest and apoptosis in glioblastoma stem-like cells by WP1193, a novel small molecule inhibitor of the JAK2/STAT3 pathway," Journal of Neuro-Oncology, vol. 107, no. 3, pp. 487-501, 2012.

[103] G. Gargiulo, M. Cesaroni, M. Serresi et al., "In vivo RNAi screen for BMI1 targets identifies TGF- $\beta$ /BMP-ER stress pathways as key regulators of neural- and malignant glioma-stem cell homeostasis," Cancer Cell, vol. 23, no. 5, pp. 660-676, 2013.

[104] L. Jiang, J. Wu, Y. Yang et al., "Bmi-1 promotes the aggressiveness of glioma via activating the NF-kappaB/MMP-9 signaling pathway," BMC Cancer, vol. 12, article 406, 2012.

[105] S. He, T. Iwashita, J. Buchstaller, A. V. Molofsky, D. Thomas, and S. J. Morrison, "Bmi-1 over-expression in neural stem/progenitor cells increases proliferation and neurogenesis in culture but has little effect on these functions in vivo," Developmental Biology, vol. 328, no. 2, pp. 257-272, 2009.

[106] D. H. Meijer, M. F. Kane, S. Mehta et al., "Separated at birth? The functional and molecular divergence of OLIG1 and OLIG2," Nature Reviews Neuroscience, vol. 13, no. 12, pp. 819-831, 2012.

[107] S. Mehta, E. Huillard, S. Kesari et al., "The central nervous system-restricted transcription factor Olig2 opposes p53 responses to genotoxic damage in neural progenitors and malignant glioma," Cancer Cell, vol. 19, no. 3, pp. 359-371, 2011.

[108] Y. Sun, D. H. Meijer, J. A. Alberta et al., "Phosphorylation state of Olig2 regulates proliferation of neural progenitors," Neuron, vol. 69, no. 5, pp. 906-917, 2011.

[109] J. D. Dougherty, E. I. Fomchenko, A. A. Akuffo et al., "Candidate pathways for promoting differentiation or quiescence of oligodendrocyte progenitor-like cells in glioma," Cancer Research, vol. 72, no. 18, pp. 4856-4868, 2012.

[110] L. Cheng, S. Bao, and J. N. Rich, "Potential therapeutic implications of cancer stem cells in glioblastoma," Biochemical Pharmacology, vol. 80, no. 5, pp. 654-665, 2010.

[111] Z. Du, D. Jia, S. Liu et al., "Oct4 in expressed in human gliomas and promotes colony formation in glioma cells," Glia, vol. 57, no. 7, pp. 724-733, 2009.
[112] H. Ikushima, T. Todo, Y. Ino, M. Takahashi, K. Miyazawa, and K. Miyazono, "Autocrine TGF- $\beta$ signaling maintains tumorigenicity of glioma-initiating cells through Sry-related HMGbox factors," Cell Stem Cell, vol. 5, no. 5, pp. 504-514, 2009.

[113] Y. Yoshida, K. Takahashi, K. Okita, T. Ichisaka, and S. Yamanaka, "Hypoxia enhances the generation of induced pluripotent stem cells," Cell Stem Cell, vol. 5, no. 3, pp. 237-241, 2009.

[114] T. Elsir, P. H. Edqvist, J. Carlson et al., "A study of embryonic stem cell-related proteins in human astrocytomas: identification of Nanog as a predictor of survival," International Journal of Cancer, vol. 134, no. 5, pp. 1123-1131, 2014.

[115] D. L. Schonberg, D. Lubelski, T. E. Miller, and J. N. Rich, "Brain tumor stem cells: molecular characteristics and their impact on therapy," Molecular Aspects of Medicine, 2013. 

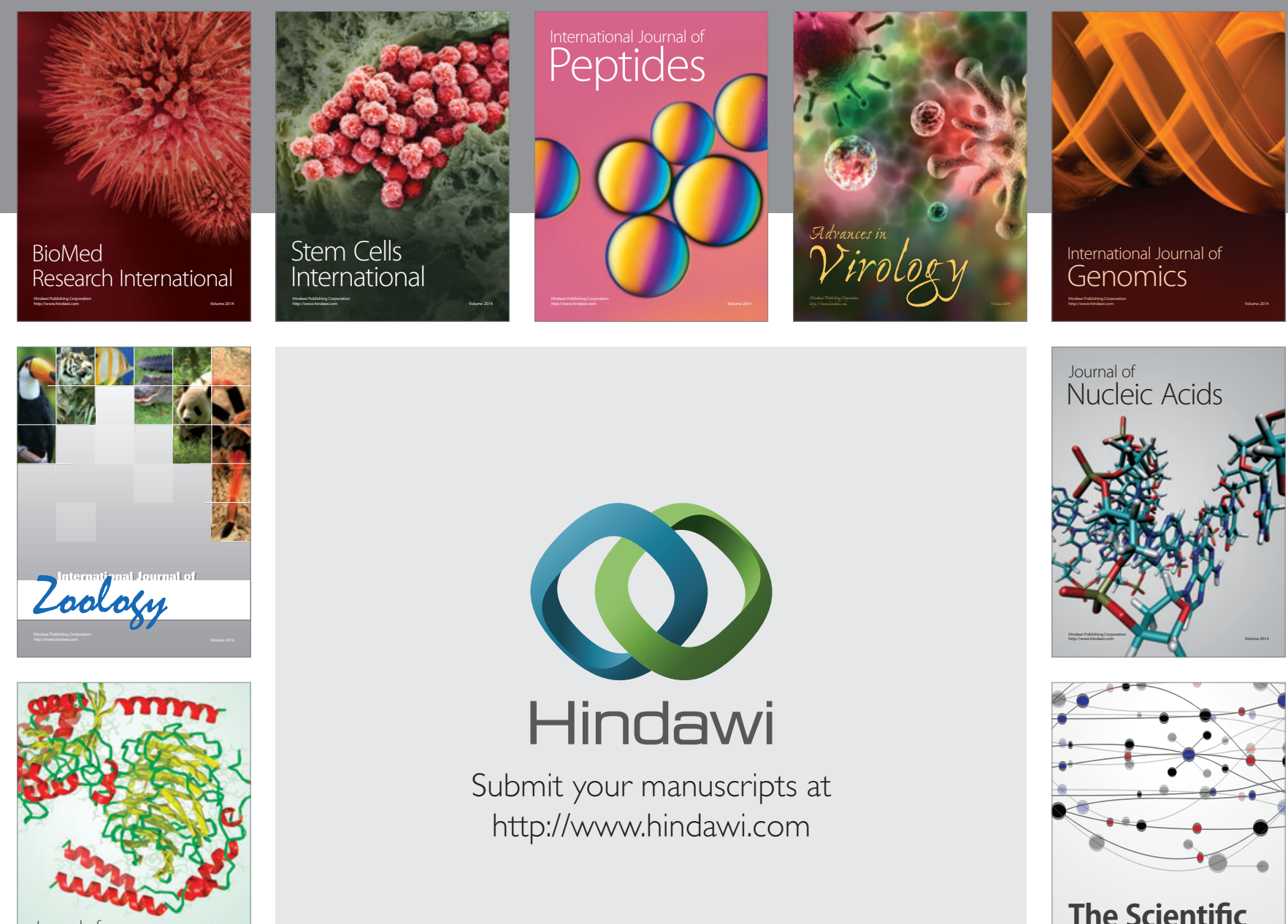

Submit your manuscripts at

http://www.hindawi.com

Journal of
Signal Transduction
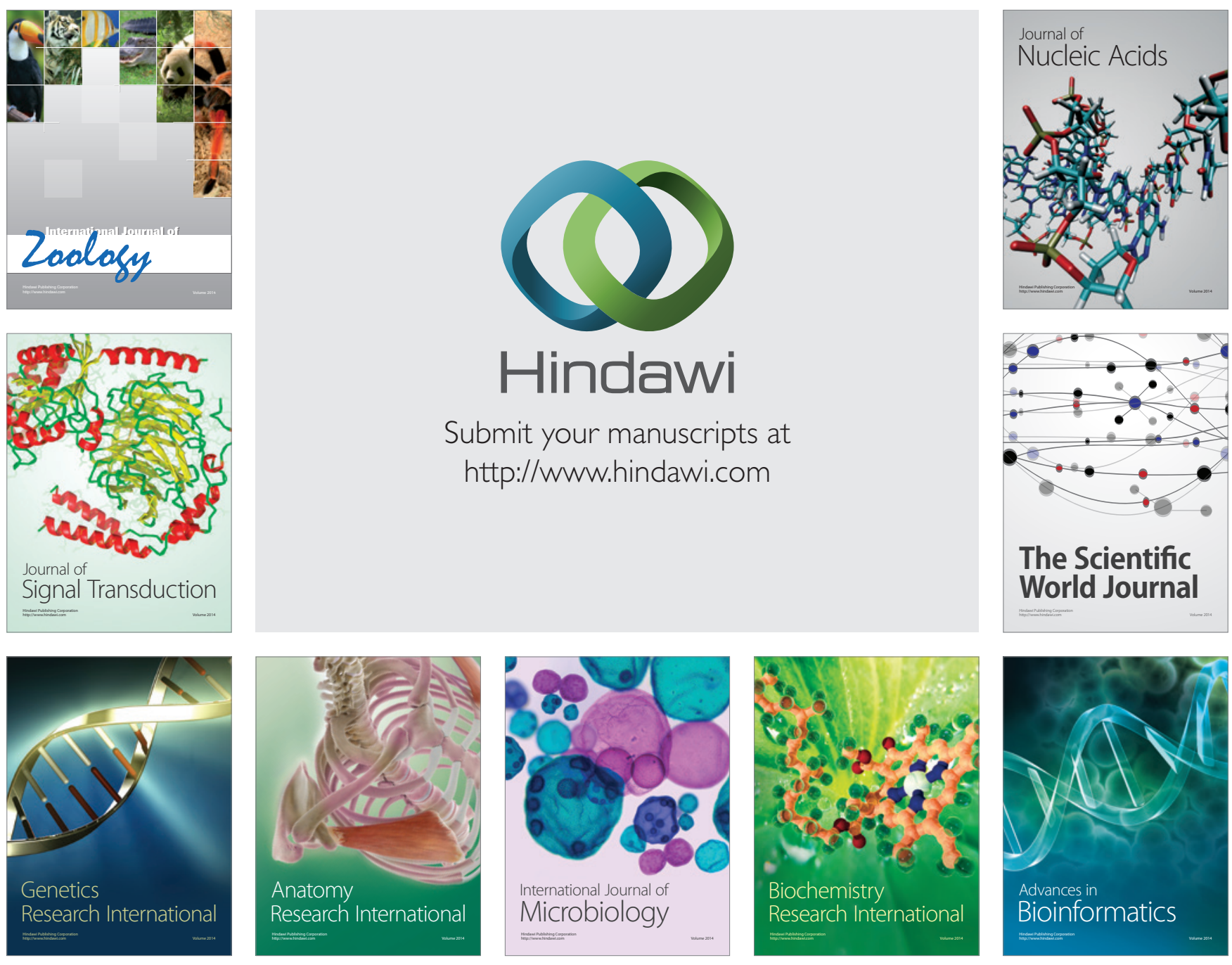

The Scientific World Journal
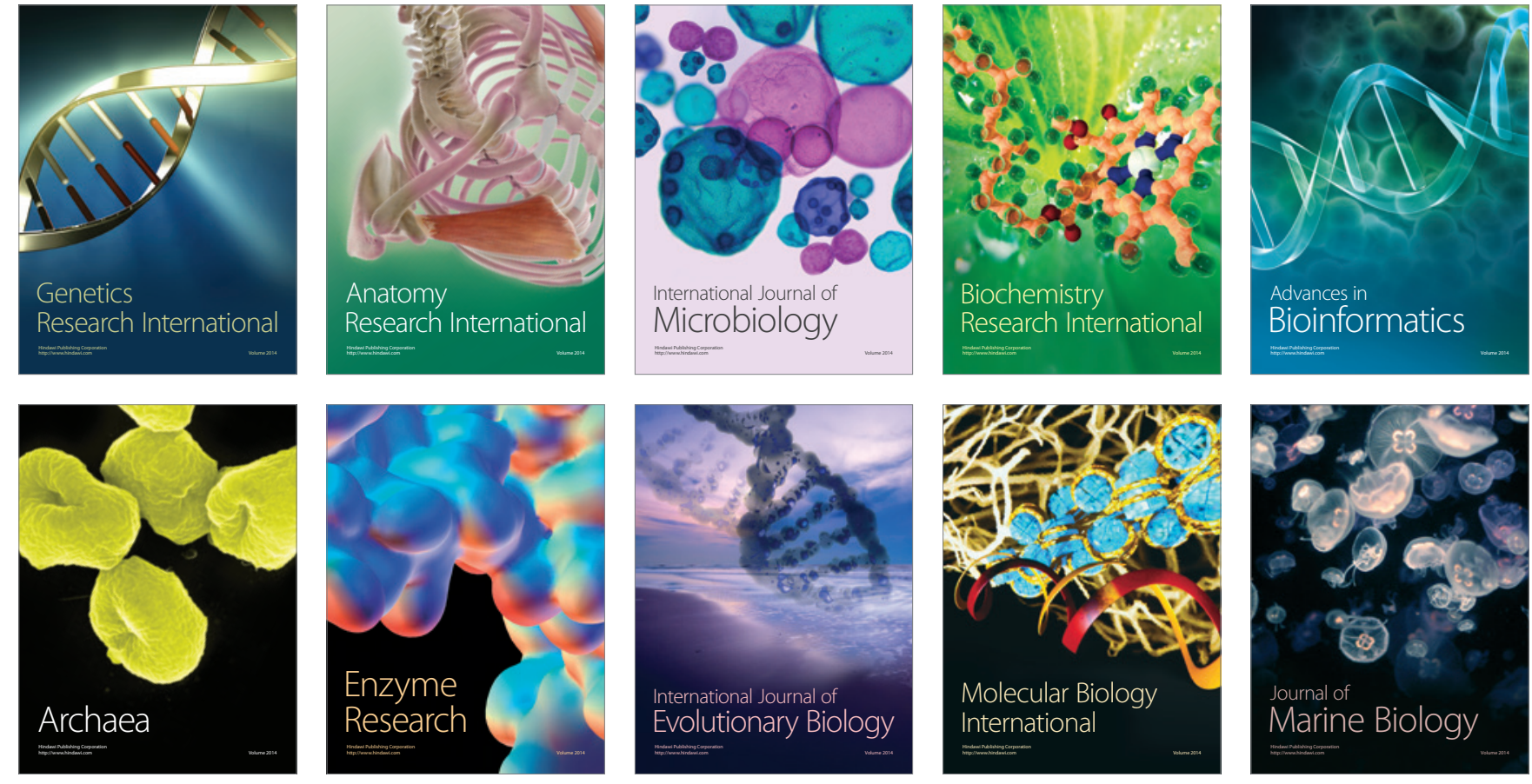